\title{
2 Technical challenges in tackling regulatory concerns for 3 urban atmospheric nanoparticles
}

4 Prashant Kumar $^{\mathrm{a}, \mathbf{b}^{, *}, \text { Alan Robins }}{ }^{\mathrm{b}}$, Sotiris Vardoulakis ${ }^{\mathbf{c}}$, and Paul Quincey ${ }^{\mathrm{d}}$

$5 \quad{ }^{a}$ Division of Civil, Chemical and Environmental Engineering, Faculty of Engineering and 6 Physical Sciences (FEPS), University of Surrey, Guildford GU2 7XH, United Kingdom

$7{ }^{\mathrm{b}}$ Environmental Flow (EnFlo) Research Centre, FEPS, University of Surrey, Guildford GU2 7XH, 8 United Kingdom

$9{ }^{\mathrm{c} C e n t r e ~ f o r ~ R a d i a t i o n, ~ C h e m i c a l ~ a n d ~ E n v i r o n m e n t a l ~ H a z a r d s, ~ H e a l t h ~ P r o t e c t i o n ~ A g e n c y, ~ C h i l t o n, ~}$ 10 Oxon OX11 ORQ, United Kingdom

11 dAnalytical Science Division, National Physical Laboratory, Teddington, Middlesex TW11 OLW, 12 United Kingdom

\section{Abstract}

14 Recent Euro-5 and Euro-6 vehicle emission standards are the first ever initiative to 15 control particles on a number basis at the source. Related standards are also desirable 16 for ambient nanoparticles (taken in this article to be those below $300 \mathrm{~nm}$ ) to protect 17 against possible adverse impacts on public health and the environment. However, 18 there are a number of technical challenges that need to be tackled before developing a 19 regulatory framework for atmospheric nanoparticles. Some of the challenges derive from a lack of standardisation of the key measurement parameters, including sampling, necessary for robust evaluation of particle number concentrations, especially in the context of insufficient knowledge of the physicochemical characteristics of emerging sources (i.e. bio-fuel derived and manufactured nanoparticles). Ideally, ambient concentrations of primary particles could be linked to primary particle emissions by use of nanoparticle dispersion models, and secondary nanoparticles using photochemical modelling tools. The limitations in these areas are discussed. Although there is inadequate information on the exact biological mechanism through which these particles cause harm, it is argued that this should not in itself delay the introduction of regulation. This article reviews the missing links between the existing knowledge of nanoparticle number concentrations and the advances required to tackle the technical challenges implied in developing regulations.

Keywords: Airborne and manufactured nanoparticles; Particle number concentrations; Size distributions; Street canyons; Ultrafine particles; Vehicle emissions

\section{Introduction}

The dominant pathway for population exposure to nanoparticles is through the inhalation of polluted air. Toxicological studies associate exposure to nanoparticles with adverse health effects (Murr \& Garza, 2009) and show that a significant number

\footnotetext{
*Corresponding author. Division of Civil, Chemical and Environmental Engineering, Civil Engineering (C5), University of Surrey, Guildford GU2 7XH, UK; Tel.: +44 1483 682762; Fax: +44 1483 682135. Email addresses: P.Kumar@ surrey.ac.uk, Prashant.Kumar@cantab.net
} 
of mortalities may result in megacities (Kumar, Gurjar, Nagpure, \& Harrison, 2011).

2 Nanoparticles readily coagulate with larger sized particles and grow to sizes where 3 their optical properties may adversely affect urban visibility (Horvath, 1994). They 4 also affect global climate, both through direct optical effects and indirect effects via cloud formation (Buseck \& Adachi, 2008). The main source of primary particles in urban air is vehicle emissions, followed by emissions from industry. Secondary particles, formed through photochemically induced nucleation from gaseous precursors, can dominate concentrations when an episode is in progress (Holmes, 2007).

It is important to identify the size range that is most relevant to atmospheric particles from the number concentration point of view. Particles below $300 \mathrm{~nm}$ (referred to here as nanoparticles) appear to be by far the most numerous (i.e. over $99 \%$ of the total particle number concentrations) in urban atmospheric environments (Kumar, Fennell, \& Britter, 2008; Kumar, Garmory, Ketzel, Berkowicz, \& Britter, 2009), with the ultrafine range (those below $100 \mathrm{~nm}$ ) being the main contributor (at about $80 \%$ of the total) (Kumar, Fennell, Hayhurst, \& Britter, 2009). Consistent with this, Tuch et al. (1997) and Wehner and Wiedensohler (2003) found negligible number concentrations for particles sizes greater than $500 \mathrm{~nm}$ in European urban environments. The relevant lower size limit is more contentious. Significant numbers of particles are expected down to $1 \mathrm{~nm}$ and below. However, accurate measurements become more difficult below about $20 \mathrm{~nm}$ due to instrumentation and sampling losses.

The distributions of concentrations in the size ranges of interest vary dramatically with time and location. For example, Charron and Harrison (2003) observed that particles in the $11-100 \mathrm{~nm}$ size range represented 71 to $95 \%$ of total number concentrations in central London. Similar results were reported by Woo, Chen, Pui, \& McMurry (2001) for Atlanta (USA), showing up to $89 \%$ of total particle numbers in the size range below $100 \mathrm{~nm}$. It is important to note that a significant contribution to these concentrations derives from particles below $10 \mathrm{~nm}$ that typically arise from secondary formation (Kulmala et al., 2004). This contribution was found to be in the range of $36-44 \%$ at road sides in Birmingham, UK (Shi, Evans, Khan, \& Harrison, 2001) and generally about $25 \%$ in urban areas of Pittsburgh, USA (Stanier, Khlystov, \& Pandis, 2004) and Atlanta, USA (Woo, Chen, Pui, \& McMurry, 2001). Likewise, Wehner and Wiedensohler (2003) found 16 to $24 \%$ of total number concentrations in the 3 to $10 \mathrm{~nm}$ range in Leipzig (Germany) and Kumar et al. (2009) reported slightly smaller contributions (4 to 12\%) in Cambridge (UK) for the 5 to $10 \mathrm{~nm}$ size range.

Current regulations in the UK, Europe and elsewhere for controlling atmospheric particulate matter are based on the mass concentrations of particles $\leq 2.5 \mu \mathrm{m}\left(\mathrm{PM}_{2.5}\right)$ and $\leq 10 \mu \mathrm{m}\left(\mathrm{PM}_{10}\right)$. These metrics are dominated by larger particles rather than nanoparticles. The Euro-5 and Euro-6 emission standards are first ever regulations for particle numbers, applying to vehicle tailpipe exhausts. The measurement protocols developed by the UNECE GPRE Particle Measurement Programme are an integral part of this regulation, notably including a requirement to remove volatile particles (through heating and dilution), as these would lead to large variations in the results, and a lower size limit of $23 \mathrm{~nm}$, to minimise the effects of both small volatile particles and diffusion losses during sampling. These emission limits will soon be applicable to light duty diesel vehicles used in the European community. One of the reasons to move to number emission standards was that the precision of mass-based 
method was insufficient to provide reliable regulation of emissions from vehicles with particle traps. These regulations control the emissions of nanoparticle numbers at the source, not at the receptor. Similar standards for atmospheric nanoparticles are desirable to limit public exposure. By analogy with vehicle emission regulation, it is not necessary to have determined the specific cause of health effects before initiating regulation. However, this is still some way off and a number of unanswered issues need to be addressed before a regulatory framework for number concentrations of atmospheric nanoparticles can be proposed.

Some of the key issues that are discussed in subsequent sections are: (i) the choice of the most appropriate regulatory metric, (ii) the effect of emerging sources of nanoparticles (e.g. from bio-fuel vehicles and manufactured nanomaterials), (iii) issues affecting the accuracy of measurements, and (iv) the link between emissions and atmospheric concentrations via dispersion modelling. Other important topics such as toxicology and epidemiology policy and governance implications are not covered in detail due to the brevity of the article but the readers are directed towards the relevant literature.

\section{Particle number concentration as an appropriate regulatory metric}

Metrics for describing the environmental effects of nanoparticles have been a subject of debate for some years, a debate constrained by the limited knowledge of nanoparticle toxicity or even the precise biological mechanisms that affect human health. Adverse health effects have been mainly associated with different fractions of particle mass concentration (e.g. $\mathrm{PM}_{10}$ and $\mathrm{PM}_{2.5}$ ) although other particle characteristics (number, surface area, shape, size, composition) may be important from a human health point of view. However, consensus has not been reached for the most appropriate metric. Several studies support the contention that particle number concentrations are an important indicator of toxicity (Donaldson et al., 2005). These also report evidence of the potential detrimental effects of the ultrafine fraction $(<100$ $\mathrm{nm}$ ) on human health, though the existing body of epidemiological evidence is insufficient to define an exposure-response relationship. Particle number concentration may not be the only important metric but the evidence is that it is clearly an important metric, though whether for the whole size range of nanoparticles, or some sub-range (perhaps the ultrafine size range) is not certain. That being so, improved understanding of nanoparticle size distributions and related health effects is essential. A measure of particle number concentration seems to be an appropriate metric for ambient measurements, especially as the number based Euro-5 and Euro-6 vehicle emission standards will soon be in place (EU, 2008). The importance of defining the required particle size range, the effect of composition on this parameter, and the treatment of volatile particles are discussed in Section 4.

\section{Effects of emerging sources of nanoparticles}

Nanoparticles originate from both natural (biomass burning, volcano, biogenic, etc.) and anthropogenic (road vehicles, power plants etc.) sources. Vehicle emissions are the dominant anthropogenic source and are consequently the target for regulatory action. They can contribute up to $\sim 90 \%$ of total particle numbers in polluted urban environments (Pey et al., 2009), where emissions, mostly in the $<300 \mathrm{~nm}$ size range, can increase number concentrations of nanoparticles by two orders of magnitude or

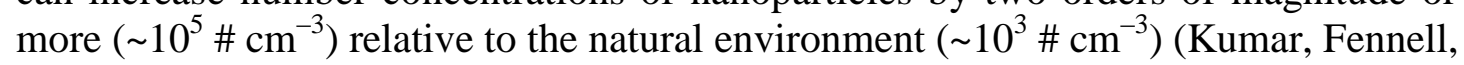


Langley, \& Britter, 2008), though concentrations are highly dependent on meteorological conditions and the formation of secondary particles. These observations clearly indicate a primary need to control vehicle emissions, as enforced through Euro emission standards, in order to limit urban nanoparticle numbers. However, future challenges include tackling emerging sources (e.g. bio-fuel derived and manufactured nanoparticles) that have different physicochemical characteristics to the nanoparticles produced from conventional sources.

\subsection{Bio-fuel derived nanoparticles}

International energy policy encourages the use of bio-fuels as a substitute for petroleum fuels in vehicles, though socio-economic issues such as food security (Dominguez-Faus, Powers, Burken, \& Alvarez, 2009) and resistance from car and components manufacturing companies, private users and local administrations has resulted in a somewhat slow uptake (Lapuerta, Armas, \& Fernandez, 2008). The reasons for prompting bio-fuels include energy security, foreign exchange savings, socio-economic issues, such as new employment opportunities, and environmental concerns related to greenhouse gas emissions (Hammond, Kallu, \& McManus, 2008). For example, the European directive 2003/30/EC set an immediate legal aim of replacing $5.75 \%$ and $20 \%$ of conventional fuel in road transportation with bio-fuels by 2010 and 2020, respectively, and use of bio-fuels is on track to meet these aims. However, this has not decreased particle number emissions because of (i) a shift in number distributions towards smaller size ranges (Cheng et al., 2008), (ii) the reduced available surface area of pre-existing particles in emissions that favour nucleation over adsorption (Kittelson, Watts, \& Johnson, 2004), and (iii) the lower calorific value of bio-fuels, leading to increased fuel usage (Lapuerta, Armas, \& RodríguezFernández, 2008). Exhaust-treatment systems, such as diesel particulate filters (DPF), have been found to decrease nanoparticle emissions by up to two orders of magnitude as compared to non-DPF bio-diesel vehicles (Lee, Myung, \& Park, 2009), at least in the size range above $23 \mathrm{~nm}$. This can ensure compliance with vehicle emission standards in most cases but does not hide the fact that the use of bio-fuels in vehicles results in an overall increase in nanoparticle numbers when compared to petroleum fuels. Moreover, only somewhat limited and inconsistent information is available on the physicochemical characteristics of bio-fuel derived nanoparticles, such as size, shape, chemical composition and toxicity (Fontarasa et al., 2009; Jung, Kittelson, \& Zachariah, 2006). This confounds arguments concerning whether or not bio-fuel derived nanoparticles will complicate existing regulatory concerns with other airborne nanoparticles. The positives about bio-fuel derived nanoparticles are that their physical characteristics (i.e. shape, size) can be assumed to be similar to those from conventional fuels and the same instruments can therefore be applied to measure them (see Section 4.1). However, their chemical characteristics (which relate to toxicity) remain a less understood matter that could significantly influence the development of mitigation strategies (Bunger et al., 2000; Finch et al., 2002). Further details on this topic can be seen elsewhere (Basha, Gopal, \& Jebaraj, 2009; Kumar, Robins, \& ApSimon, 2010; Lapuerta, Armas, \& Rodríguez-Fernández, 2008; and references therein).

\subsection{Manufactured or engineered nanoparticles}

Manufactured nanomaterials (e.g. carbon nanotubes, nanowires etc.) are another 
emerging class of atmospheric nanoparticles. Their production and use are rapidly increasing as new applications emerge. This, combined with their supposed persistence against degradation, implies that human and environmental exposure to so-called engineered nanoparticles will increase (Köhler, Som, Helland, \& Gottschalk, 2008). They are not intentionally released into the urban environment but fugitive emissions can arise during production, use and disposal, though source terms are not well understood, neither are potential health effects (Brouwer, 2010; Nowack \& Bucheli, 2007). Their physicochemical characteristics differ from atmospheric nanoparticles in numerous ways, such as aspect ratio, size distribution, chemical composition, toxicity and homogeneity (Xia, Li, \& Nel, 2009). Recent studies report that inorganic or carbon nanostructures do not cause acute toxic effects at low doses, but prolonged exposure could well lead to adverse human health effects (Casals, Vázquez-Campos, Bastús, \& Puntes, 2008). However, the relative toxicity of the two kinds of nanoparticles (atmospheric and manufactured) is currently not well known. Kumar, Fennell, \& Robins (2010) recently reviewed the behaviour of manufactured and other airborne nanoparticles and discussed their significance in prioritising research and regulation activities. This concluded that the differences between manufactured and other atmospheric nanoparticles must be understood and specific measurement methods developed for regulatory control. The current knowledge of the characteristics and behaviour of air dispersed manufactured nanoparticles appears to be insufficient to influence any potential regulatory framework for atmospheric nanoparticles as a whole. Though their concentration relative to other atmospheric particles is currently very small., it will continue to grow, driven by the expected widespread use of products incorporating manufactured nanomaterials (e.g. batteries and textiles; Köhler et al., 2008). The current emphasis on developing innovative methods for detecting manufactured nanoparticles in the environment or workplace through exploiting their specific properties (i.e. magnetic, optical, electrical, electrochemical or physical) should eventually provide precise information on their behaviour in the atmosphere.

\section{Key challenges in measurements and dispersion modelling of nanoparticle number concentration}

There have been substantial advances in instrumentation for measuring nanoparticle number concentrations and size distributions, but there are as yet no standard application methods and sampling guidelines for measurement in the urban atmospheric environment. An initiative is needed for urban nanoparticle instrumentation that is similar to the Particle Measurement Programme that is establishing new systems and protocols for assessing nanoparticle emissions from vehicles (EU, 2008). This would seek to harmonise the performance of instruments in different ambient environments and establish standard guidelines for their use.

\subsection{Instruments}

The generally accepted instrument for measuring particle number concentration is the Condensation Particle Counter (CPC). However, before a CPC-based standard can be proposed, the desired performance characteristics need to be agreed. This mainly applies to the low-size detection cut-off, which itself depends on the particle material, as this affects the condensation of the working fluid around the particle. Within Europe, standardisation is currently underway in the European Committee for Standardisation (CEN) to define a cut-off curve for a specific particle material with a 
specific working fluid. At the same time, procedures to determine CPC detection

2 efficiencies are being defined within ISO. The instrumentation aspects of number

3 concentration measurements are therefore being addressed.

4 In principle, size resolved particle number concentration measurements would be 5 more useful than CPC measurements. There are several instruments available, based 6 on established methods of size selection and detection. These include Scanning 7 Mobility Particle Sizers (SMPS), Electrical Low Pressure Impactors, Aerodynamic 8 Particle Sizers, Differential Mobility Spectrometers, and Laser Aerosol 9 Spectrometers. A comprehensive review of their capabilities and limitations can be 10 seen in Kumar, Robins, Vardoulakis \& Britter (2010). Most of the above instruments 11 claim to overcome important issues such as portability, time response, size resolution, 12 robustness for unattended operation over long durations, calibration and maintenance 13 requirements. However, the relative higher cost for widespread deployment and the 14 reproducibility of data still remains as major issues. For example, Asbach et al. (2009) benchmark instrument, and found a significant inconsistencies in measured distributions. This is because the different sizing principles would be expected to lead to significant differences for non-spherical particles. Likewise, Watson et al. (2011) compared hourly averaged ambient particle number and size distribution measurements which were taken simultaneously by 4 commercially available SMPS systems. They found similar shape of size distributions but with notable discrepancies in average concentrations for small $(5-10 \mathrm{~nm})$ and large $(200-300 \mathrm{~nm})$ particle size ranges. Moreover, the SMPS may have its own limitations related to its time response, portability and particle characterisation. For example, an HSE (2006) report observed that under certain circumstances the SMPS has the potential to alter the structure of the sampled particles due to the bi-polar charging process it employs in the size classification of the aerosol. All the above observations make judgement of equipment performance for particle size distribution difficult; e.g. in understanding the repeatability and reproducibility of results from different instruments in nominally identical conditions. Ideally, instruments with high sampling frequencies, covering a wide range of particle sizes (from $3 \mathrm{~nm}$ to $10 \mu \mathrm{m}$ ) and robust enough to operate unattended for long periods at urban monitoring stations are needed at modest cost for widespread deployment to characterise individual and population exposure to nanoparticles at specific sizes in urban environments (Kumar, Robins, Vardoulakis et al., 2010). All these capabilities are not currently met by a single particle monitoring instrument and use of more than one instrument is required to obtain such a combination.

\subsection{Sampling}

Standardisation of sampling methods and data handling is also essential for improving the reproducibility of measurements. For example, Wiedensohler (2010) proposed methods for particle sampling and humidity control during field measurements. Atmospheric particles can undergo significant hygroscopic growth (e.g. $\sim 1.5$ time increase in size) at high $(\sim 80 \%)$ relative humilities $(\mathrm{RH})$ and maintaining the RH below $40-50 \%$ in the sampling system is recommended for determining the physical properties of particles. Other recommendations for sampling methods include the use a separate vertical stack for particle measurements with an high sampling efficiency inlet capable of handling wide range of wind speeds; use of 
weather and sunlight-resistant, conductive and non-corrosive material for sampling tubes; calibrations of size and flow using latex particles and an independent volume flow meter, respectively; and maintaining a laminar flow within the sampling tubes (Reynolds number 2000) to avoid losses of particles due to diffusion and turbulent inertial deposition (Wiedensohler, 2010). Although inertial impaction is in theory only important under turbulent flow conditions and for particles larger than $100 \mathrm{~nm}$ (Lee \& Gieseke, 1994), particle losses onto the inner surface of the sampling tubes can occur even at low Reynolds number flow in long sampling tubes, as are often required during field measurements, and this can appreciably change the measured number and size distributions. For example, a recent study (Kumar, Fennell, Symonds, \& Britter, 2008) demonstrated that that the turbulent penetration model of Hinds (1999) described particle losses best, even when the flow within the sampling tube during field measurements was in the laminar region (i.e. Reynolds number $\sim 461$ ). This was presumably due to the formation of secondary flows and other unknown complications. Losses were found to be greatest for particles below $20 \mathrm{~nm}$, due to the higher diffusivity of smaller particles. The study concluded that an in-situ calibration or comparison is prudent to evaluate the losses of particles in any experimental setup.

In contrast to vehicle emissions, there is much less intrinsic benefit in removing volatile particles during the sampling process in ambient air. Unless evidence from health effects requires only non-volatile particles to be measured, the aim should be to minimise volatile losses during sampling. In general, this is not a major problem as sampling and measurement do not involve elevated temperatures.

\subsection{Dispersion modelling}

Several models are currently available for particle dispersion at various urban scales. These include Box, Gausssian, Lagrangian, Eulerian and Computational Fluid Dynamics models, including models that treat particle dynamics (Holmes \& Morawska, 2006; Vardoulakis, Fisher, Pericleous, \& Gonzalez-Flesca, 2003). Validation studies for particle number prediction are not abundant because of the lack of both long-term measurements that include size distributions of nanoparticles and accurate input information (i.e. emission factors, meteorology, local traffic and the geometry of the site, etc.). This limits the use of particle dispersion models, which themselves contain both structural (errors in model formation) and parametric (due to model input parameters) uncertainties (COSTAction732, 2010). For example, Lohmeyer (2001) reported that predictions of gaseous pollutants from different models can vary up to a factor of four for identical conditions, depending on the quality of input information. Moreover, the prediction of particles on a number basis becomes more complicated when removal (i.e. dry or wet depositions) and transformation (i.e. nucleation, coagulation, condensation and evaporation) processes are incorporated into the models. This is because all chemical and physical processes show a strong non-linear dependency on particle sizes, that itself varies over a very wide range. There is limited information available on the removal and transformation processes that occur after the release of exhaust emissions but play an important role in changing particle size distributions at different urban scales (i.e. in vehicle wake, street canyons and city) (Hinds, 1999; Jacobson \& Seinfeld, 2004; Ketzel \& Berkowicz, 2004; Kumar, Robins, \& Britter, 2009; Pohjola, Pirjola, Kukkonen, \& Kulmala, 2003; Wehner, Birmili, Gnauk, \& Wiedensohler, 2002). Complex flow and mixing due to intricate networks of streets and buildings, synoptic scale winds, 
surface heating and distributed pollution sources (such as moving traffic in urban areas) make this problem even more challenging (Britter \& Hanna, 2003). Detailed information on the dynamics and dispersion modelling of urban atmospheric nanoparticles at different urban scales can be seen in a recent review by Kumar, Ketzel, Vardoulakis, Britter, \& Pirjola (2011). Although not strictly necessary for regulation, improved understanding of dispersion modelling at all urban scales would greatly help the development of future strategies to reduce concentrations of urban atmospheric nanoparticles.

Despite the limitations imposed by available instrumentation, there has recently been a significant increase in the number of studies of urban nanoparticle concentrations and size distributions, though not sufficient to inform regulatory decision making on a particle number basis. Within the United Kingdom, for example, particle number concentration (in the size range from $7 \mathrm{~nm}$ up to several micrometers) and size distribution (between about 16 and $600 \mathrm{~nm}$ ) have been measured continually at several locations for more than 10 years. Typical reported concentrations range from about $5,000 \# \mathrm{~cm}^{-3}$ at a rural site to $100,000 \mathrm{Cm}^{-3}$ at an urban kerbside site (Beccaceci et al., 2010). Such measurements need to become widespread to provide a comprehensive data-base that can be analysed to understand better the effects of meteorology, traffic volume and particle dynamics as a function of nanoparticle size range. Ideally, this would also cover transformation and transport behaviour from the tailpipe-to-roadside-to-urban background and could serve as validation data for performance evaluation of particle dispersion models (Kumar, Robins, Vardoulakis et al., 2010). It could also be the key to establishing reliable particle number emission factors, one of the most important input parameters for any particle dispersion model. There is currently large associated uncertainty (i.e. up to an order of magnitude for a given vehicle type under nearly identical driving conditions) in both their measurement and estimation (Keogh et al., 2009; Kumar, Ketzel, Vardoulakis, Britter, \& Pirjola, 2011). A comprehensive data-base will support the development of better dispersion models for nanoparticle numbers as well as provide the additional input needed for their application.

\section{Summary and conclusions}

There is presently no legal threshold anywhere in the world for controlling the exposure of the public to airborne particle number concentrations in the urban environment. There are several reasons for this, including a lack of standardisation for sampling and measurement, as well as a lack of clear epidemiological evidence (Xia et al., 2009). Properly validated particle dispersion models would also be helpful (Holmes \& Morawska, 2006; Vardoulakis et al., 2003). Despite this, understanding of the sources, dispersion and physicochemical characteristics of atmospheric nanoparticles has increased substantially in recent years, as has the availability of suitable monitoring systems. In line with these advances, air quality monitoring networks should be encouraged to use currently available instrumentation to include measurements of number and size distributions of nanoparticles. Such initiatives will provide the data that will help address the issues raised in this article, along with an opportunity for comprehensive validation of particle dispersion models (Kumar, Ketzel, Vardoulakis, Britter, \& Pirjola, 2011). The data would also provide a valuable input for decision-makers to help develop research and mitigation strategies for controlling nanoparticles on a number basis in the urban environment. 


\section{Acknowledgements}

The motivation for this work came from an EPSRC grant (EP/H026290/1), awarded to PK, on nanoparticles dispersion in vehicle wakes.

\section{References}

Asbach, C., Kaminski, H., Fissan, H., Monz, C., Dahmann, D., Mu“lhopt, S., et al. (2009). Comparison of four mobility particle sizers with different time resolution for stationary exposure measurements Journal of Nanoparticle Research, 11, 1593-1609.

Basha, S. A., Gopal, K. R., \& Jebaraj, S. (2009). A review on biodiesel production, combustion, emissions and performance. Renewable and Sustainable Energy Reviews, 13(6-7), 16281634.

Beccaceci, S., Muhunthan, D., Butterfield, D., Gilham, R., Tompkins, J., Sweeney, B., Brown, R., Quincey, P., Green, D., Alexander, J., and Grieve, A., (2010). CPEA 28: Airborne Particulate Concentrations and Numbers in the United Kingdom (phase 2) Annual Report - 2009, Defra Air Quality Report Library: http://uk-air.defra.gov.uk/library/

Britter, R. E., \& Hanna, S. R. (2003). Flow and dispersion in urban areas. Annual Review of Fluid Mechanics, 35, 469-496.

Brouwer, D. (2010). Exposure to manufactured nanoparticles in different workplaces. Toxicology, 269, 120-127.

Bunger, J., Krahl, J., Baum, K., Schroder, O., Muller, M., \& Westphal, G. (2000). Cytotoxic and mutagenic effects, particle size and concentration analysis of diesel engine emissions using biodiesel and petrol diesel as fuel. Archives of Toxicology, 74, 490-498.

Buseck, P. R., \& Adachi, K. (2008). Nanoparticles in the atmosphere. Elements, 4(6), 389-394.

Casals, E., Vázquez-Campos, S., Bastús, N. G., \& Puntes, V. (2008). Distribution and potential toxicity of engineered inorganic nanoparticles and carbon nanostructures in biological systems. Trends in Analytical Chemistry 27, 672-683

Charron, A., \& Harrison, R. M. (2003). Primary particle formation from vehicle emissions during exhaust dilution in the road side atmosphere. Atmospheric Environment, 37, 4109-4119.

Cheng, C. H., Cheung, C. S., Chan, T. L., Lee, S. C., Yao, C. D., \& Tsang, K. S. (2008). Comparison of emissions of a direct injection diesel engine operating on biodiesel with emulsified and fumigated methanol. Fuel, 87(10-11), 1870-1879.

COSTAction732. (2010). Quality assurance and improvement of microscale meteorological models. COST 732 Model evaluation case studies: Approcahes and results, ISBN: 3-00018312-4, pp. 122.

Dominguez-Faus, R., Powers, S. E., Burken, J. G., \& Alvarez, P. J. (2009). The Water Footprint of Biofuels: A Drink or Drive Issue? Environmental Science \& Technology, 43(9), 30053010.

Donaldson, K., Tran, L., Albert Jimenez, L. A., Duffin, R., Newby, D. E., Mills, N., et al. (2005). Combustion-derived nanoparticles: A review of their toxicology following inhalation exposure. Particle \& Fibre Toxicology, 5/6, 553-560.

EU. (2008). Commission Regulation (EC) No 692/2008. Official Journal of the European Union, pp 136.

Finch, G. L., Hobbs, C. H., Blair, L. F., Barr, E. B., Hahn, F. F., Jaramillo, R. J., et al. (2002). Effects of subchronic inhalation exposure of rats to emissions from a diesel engine burning soybean oil-derived biodiesel fuel. Inhalation Toxicology, 14, 1017-1048.

Fontarasa, G., Karavalakisb, G., Kousoulidoua, M., Tzamkiozisa, T., Ntziachristosa, L., Bakeasc, E., et al. (2009). Effects of biodiesel on passenger car fuel consumption, regulated and non-regulated pollutant emissions over legislated and real-world driving cycles Fuel, 88, $1608-1617$.

Lee, K. W., \& Gieseke, J. A. (1994). Deposition of particles in turbulent flow pipes. Journal of Aerosol Science, 25, 699-704.

Hammond, G. P., Kallu, S., \& McManus, M. C. (2008). Development of biofuels for the UK automotive market. Applied Energy, 85(6), 506-515.

Hinds, W. C. (1999). Aerosol technology: Properties, behaviour and measurement of airborne particles: John Wiley \& Sons, UK, pp. 483. 
Holmes, N. (2007). A review of particle formation events and growth in the atmosphere in the various environments and discussion of mechanistic implications. Atmospheric Environment 41, 2183-2201.

Holmes, N. S., \& Morawska, L. (2006). A review of dispersion modelling and its application to the dispersion of particles: An overview of different dispersion models available. Atmospheric Environment, 40, 5902-5928.

Horvath, H. (1994). Atmospheric aerosols, atmospheric optics visibility. Journal of Aerosol Science 25, S23-S24.

HSE. (2006). The assessment of different metrics of the concentration of nano (ultrafine) particles in existing and new industries. Health and Safety Executive, pp. 80.

Jacobson, M. Z., \& Seinfeld, J. H. (2004). Evolution of nanoparticle size and mixing state near the point of emission. Atmospheric Environment, 38, 1839-1850.

Jung, H., Kittelson, D. B., \& Zachariah, M. R. (2006). Characteristics of SME biodiesel-fueled diesel particle emissions and the kinetics of oxidation. Environmental Science and Technology, 40(16), 4949-4955.

Keogh, D. U., Kelly, J., Mengersen, K., Jayaratne, R., Ferreira, L., \& Morawska, L. (2009). Derivation of motor vehicle tailpipe particle emission factors suitable for modelling urban fleet emissions and air quality assessments. Environmental Science and Pollution Research, 17(3), 724-739.

Ketzel, M., \& Berkowicz, R. (2004). Modelling the fate of ultrafine particles from exhaust pipe to rural background: an analysis of time scales for dilution, coagulation and deposition. Atmospheric Environment, 38(17), 2639-2652.

Kittelson, D. B., Watts, W. F., \& Johnson, J. P. (2004). Nanoparticle emissions on Minnesota highways. Atmospheric Environment 38, 9-19.

Köhler, A. R., Som, C., Helland, A., \& Gottschalk, F. (2008). Studying the potential release of carbon nanotubes throughout the application life cycle. Journal of Cleaner Production, 16(8-9), 927-937.

Kulmala, M., Vehkamaki, H., Petaja, T., Dal Maso, M., Lauri, A., Kerminen, V.-M., et al. (2004). Formation and growth rates of ultrafine particles: a review of observations. Journal of Aerosol Science, 35, 143-176.

Kumar, P., Fennell, P., \& Britter, R. (2008). Measurements of particles in the 5-1000 nm range close to road level in an urban street canyon. Science of the Total Environment, 390, 437447.

Kumar, P., Fennell, P., Hayhurst, A., \& Britter, R. E. (2009). Street versus rooftop level concentrations of fine particles in a Cambridge street canyon. Boundary-Layer Meteorology, 131, 3-18.

Kumar, P., Fennell, P., Langley, D., \& Britter, R. (2008). Pseudo-simultaneous measurements for the vertical variation of coarse, fine and ultra fine particles in an urban street canyon. Atmospheric Environment, 42(18), 4304-4319.

Kumar, P., Fennell, P., \& Robins, A. (2010). Comparison of the behaviour of manufactured and other airborne nanoparticles and the consequences for prioritising research and regulation activities. Journal of Nanoparticle Research, 12, 1523-1530.

Kumar, P., Fennell, P., Symonds, J., \& Britter, R. (2008). Treatment of losses of ultrafine aerosol particles in long cylindrical sampling tubes during ambient measurements. Atmospheric Environment, 42, 8819-8826.

Kumar, P., Garmory, A., Ketzel, M., Berkowicz, R., \& Britter, R. (2009). Comparative study of measured and modelled number concentrations of nanoparticles in an urban street canyon. Atmospheric Environment, 43, 949-958.

Kumar, P., Robins, A., \& ApSimon, H. (2010). Nanoparticle emissions from biofuelled vehicles their charcterstics and impact on the number based regulation of atmospheric nanoparticles. Atmospheric Science Letters, 11, 327-331.

Kumar, P., Robins, A., \& Britter, R. (2009). Fast response measurements for the dispersion of nanoparticles in a vehicle wake and in a street canyon. Atmospheric Environment, 43, 6110-6118.

Kumar, P., Robins, A., Vardoulakis, S., \& Britter, R. (2010). A review of the characteristics of nanoparticles in the urban atmosphere and the prospects for developing regulatory control. Atmospheric Environment, 44, 5035-5052. 
Kumar, P., Gurjar, B. R., Nagpure, A., \& Harrison, R. M. (2011). Preliminary estimates of nanoparticle number emissions from road vehicles in megacity Delhi and associated health impacts. Environmental Science and Technology, In press, doi:10.1021/es2003183.

Kumar, P., Ketzel, M., Vardoulakis, S., Britter, R., \& Pirjola, L. (2011). Dynamics and dispersion modelling of nanoparticles from road traffic in the urban atmsopheric environment - a review. Journal of Aerosol Science, revised manuscript under review.

Lapuerta, M., Armas, O., \& Fernandez, J. R. (2008). Effect of biodiesel fuels on diesel engine emissions. Progress in Energy and Combustion Science, 34, 198-223.

Lapuerta, M., Armas, O., \& Rodríguez-Fernández, J. (2008). Effect of biodiesel fuels on diesel engine emissions. Progress in Energy and Combustion Science, 34(2), 198-223.

Lee, H., Myung, C.-L., \& Park, S. (2009). Time-resolved particle emission and size distribution characteristics during dynamic engine operation conditions with ethanol-blended fuels. Fuel, 88(9), 1680-1686.

Lohmeyer, A. (2001). Comparison of the procedures of different modellers for air pollutant concentrations in a street canyon-The Podbielski Street exercise. http://www.lohmeyer.de/podbi/.

Murr, L. E., \& Garza, K. M. (2009). Natural and anthropogenic environmental nanoparticulates: Their microstructural characterization and respiratory health implications. Atmospheric Environment, 43, 2683-2692.

Nowack, B., \& Bucheli, T. D. (2007). Occurrence, behavior and effects of nanoparticles in the environment. Environmental Pollution, 150(1), 5-22.

Pey, J., Querol, X., Alastuey, A., Rodríguez, S., Putaud, J. P., \& Van Dingenen, R. (2009). Source apportionment of urban fine and ultra fine particle number concentration in a Western Mediterranean city. Atmospheric Environment, 43, 4407-4415.

Pohjola, M., Pirjola, L., Kukkonen, J., \& Kulmala, M. (2003). Modelling of the influence of aerosol processes for the dispersion of vehicular exhaust plumes in street environment. Atmospheric Environment, 37(3), 339-351.

Shi, J. P., Evans, D. E., Khan, A. A., \& Harrison, R. M. (2001). Sources and concentration of nanoparticles $(<10 \mathrm{~nm}$ diameter) in the urban atmosphere. Atmospheric Environment, 35(7), 1193-1202.

Stanier, C., Khlystov, A., \& Pandis, S. (2004a). Ambient aerosol size distributions and number concentrations measured during the Pittsburgh Air Quality Study (PAQS). Atmospheric Environment 38, 3275-3284.

Tuch, T., Brand, P., Wichmann, H. E., \& Heyder, J. (1997). Variations of particle number and mass concentration in various size ranges of ambient aerosols in eastern Germany. Atmospheric Environment, 31, 4193-4197.

Vardoulakis, S., Fisher, B. R. A., Pericleous, K., \& Gonzalez-Flesca, N. (2003). Modelling air quality in street canyons: a review. Atmospheric Environment 37, 155-182.

Watson, J. G., Chow, J. C., Sodeman, D. A., Lowenthal, D. H., Chang, M. C. O., Park, K., et al. (2011). Comparison of four scanning mobility particle sizers at the Fresno Supersite. Particuology, In Press, doi: 10.1016/j.partic.2011.03.002.

Wehner, B., Birmili, W., Gnauk, T., \& Wiedensohler, A. (2002). Particle number size distributions in a street canyon and their transformation into the urban air background: measurements and a simple model study. Atmospheric Environment 36, 2215-2223.

Wehner, B., \& Wiedensohler, A. (2003). Long term measurements of submicrometer urban aerosols: statistical analysis for correlations with meteorological conditions and trace gases. Atmospheric Chemistry Physics, 3, 867-879.

Wiedensohler, A. (2010). Problems and solutions specific to ambient aerosol measurements. Metrology of Airborne Nanoparticles, Standardisation and Applications (MANSA), NPL, June 8-9, 2010, Download from: http://www.npl.co.uk/upload/pdf/20100608_mansa_wiedensohler.pdf.

Woo, K. S., Chen, D. R., Pui, D. Y. H., \& McMurry, P. H. (2001). Measurement of Atlanta aerosol size distributions: observation of ultrafine previous term particle next term events. Aerosol Science and Technology, 34, 75-87.

Xia, T., Li, N., \& Nel, A. E. (2009). Potential Health Impact of Nanoparticles. Annual Review of Public Health, 30, 137-150. 


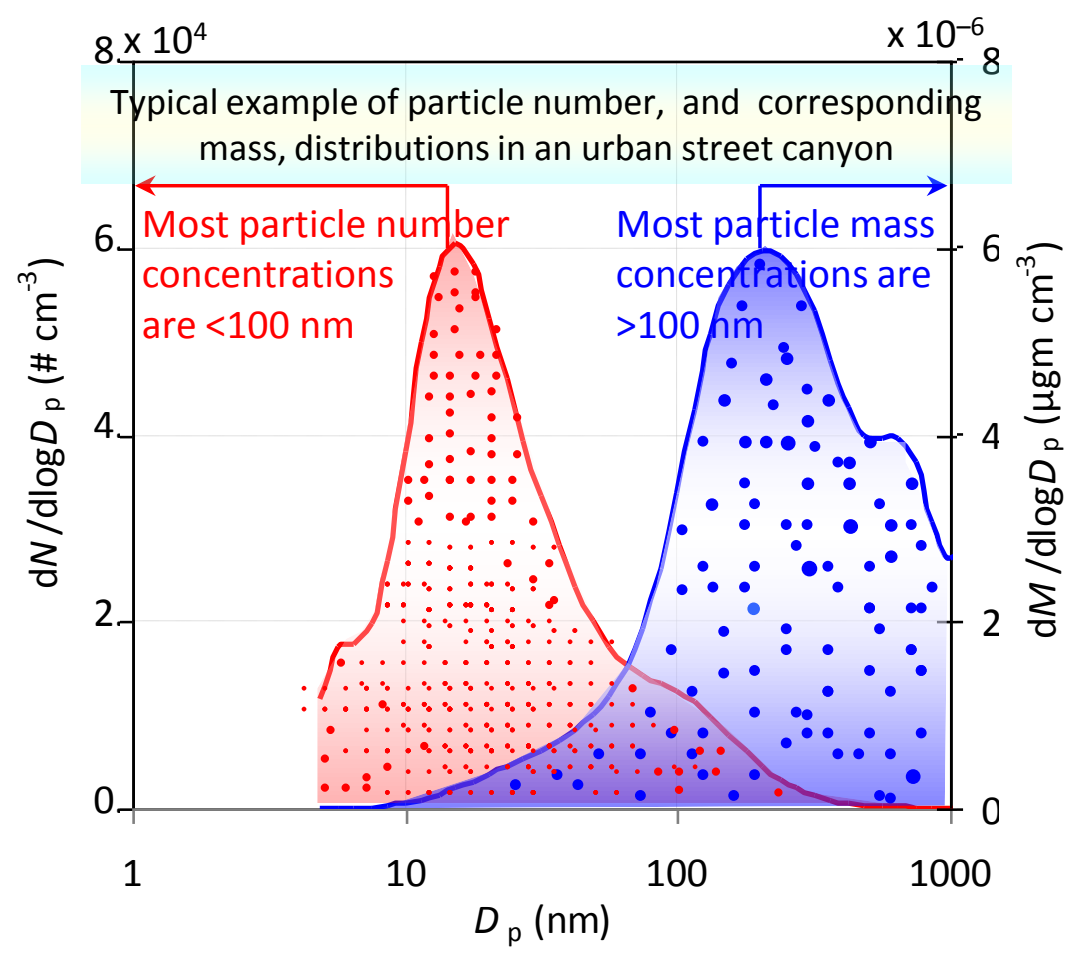

